\title{
A discovery-based proteomics approach identifies protein disulfide isomerase (PDIA1) as a biomarker of $\beta$ cell stress in type 1 diabetes
}

Farooq Syed ${ }^{1,2}$, Divya Singhal ${ }^{3}$, Koen Raedschelders ${ }^{4}$, Preethi Krishnan ${ }^{1,2}$, Robert N. Bone $^{1,2}$, Madeline R. McLaughlin ${ }^{1}$, Jennifer E. Van Eyk ${ }^{4}$, Raghavendra G. Mirmira ${ }^{5}$, MeiLing Yang ${ }^{6}$, Mark J. Mamula ${ }^{6}$, Huanmei $\mathrm{Wu}^{7,8}$, Xiaowen Liu ${ }^{9}$ and Carmella EvansMolina ${ }^{1,2,10,11,12}$

${ }^{1}$ Center for Diabetes and Metabolic Diseases, Indiana University School of Medicine, Indianapolis, IN, USA

${ }^{2}$ Department of Pediatrics and the Herman B Wells Center for Pediatric Research, Indiana University School of Medicine, Indianapolis, IN, USA

${ }^{3}$ Department of Biochemistry and Molecular Biology, University of Calgary, Calgary, Alberta, Canada

${ }^{4}$ Advanced Clinical Biosystems Research Institute, Precision Health, Barbra Streisand Women's Heart Center at the Smidt Heart Institute, Cedars-Sinai Medical Center, Los Angeles, CA, USA

${ }^{5}$ Kovler Diabetes Center, University of Chicago, Chicago, IL, USA

${ }^{6}$ Department of Medicine, Yale University School of Medicine, New Haven, CT, USA

${ }^{7}$ Department of BioHealth Informatics, Indiana University-Purdue University Indianapolis, Indianapolis, IN, USA

${ }^{8}$ Department of Health Services Administration and Policy, Temple University College of Public Health, Philadelphia, PA, USA

${ }^{9}$ Deming Department of Medicine, Tulane University School of Medicine, New Orleans, LA, USA

${ }^{10}$ Department of Medicine, Indiana University School of Medicine, Indianapolis, IN, USA

${ }^{11}$ Department of Biochemistry and Molecular Biology, Indiana University School of Medicine, Indianapolis, IN, USA

${ }^{12}$ Richard L. Roudebush VA Medical Center, Indiana University School of Informatics and Computing, Indianapolis, IN, USA

\section{*Address correspondence and requests for reprints to:}

Carmella Evans-Molina, MD, PhD (cevansmo@iu.edu), Indiana University School of Medicine, 635 Barnhill Drive, MS 2031A, Indianapolis, IN 46202, Telephone: (317) 2744145, Fax (317) 274-4107 


\begin{abstract}
Background

Activation of stress pathways intrinsic to the $\beta$ cell are thought to both accelerate $\beta$ cell death and increase $\beta$ cell immunogenicity in type 1 diabetes (T1D). However, information on the timing and scope of these responses is lacking.
\end{abstract}

\title{
Methods
}

To identify temporal and disease-related changes in islet $\beta$ cell protein expression, data independent acquisition-mass spectrometry was performed on islets collected longitudinally from NOD mice and NOD-SCID mice rendered diabetic through T cell adoptive transfer.

\section{Findings}

In islets collected from female NOD mice at 10,12 , and 14 weeks of age, we found a timerestricted upregulation of proteins involved in the maintenance of $\beta$ cell function and stress mitigation, followed by loss of expression of protective proteins that heralded diabetes onset. Pathway analysis identified EIF2 signaling and the unfolded protein response, mTOR signaling, mitochondrial function, and oxidative phosphorylation as commonly modulated pathways in both diabetic NOD mice and NOD-SCID mice rendered acutely diabetic by adoptive transfer, highlighting this core set of pathways in T1D pathogenesis. In immunofluorescence validation studies, $\beta$ cell expression of protein disulfide isomerase A1 (PDIA1) and 14-3-3b were found to be increased during disease progression in NOD islets, while PDIA1 plasma levels were increased in pre-diabetic NOD mice and in the serum of children with recent-onset T1D compared to age and sex-matched non-diabetic controls. 
bioRxiv preprint doi: https://doi.org/10.1101/2021.12.22.473924; this version posted December 23,2021 . The copyright holder for this preprint

(which was not certified by peer review) is the author/funder. This article is a US Government work. It is not subject to copyright under 17 USC 105 and is also made available for use under a CCO license.

\section{Interpretation}

We identified a common and core set of modulated pathways across distinct mouse models of T1D and identified PDIA1 as a potential human biomarker of $\beta$ cell stress in T1D.

\section{Keywords}

$\beta$ cell stress, type 1 diabetes, protein disulfide isomerase $A 1$, proteomics, biomarkers 


\section{Introduction}

Type 1 diabetes (T1D) results from an immune-mediated destruction of the insulinproducing $\beta$ cells and manifests clinically after a threshold reduction in $\beta$ cell mass and function. Data from clinical cohorts of autoantibody-positive individuals followed longitudinally suggest that $\beta$ cell function is impaired very early during disease progression, often years before the onset of clinical disease (1). In parallel, histologic studies performed on pancreatic sections from organ donors with autoantibody positivity and T1D demonstrate variable reductions in $\beta$ cell mass before and at diabetes onset (24). Findings from ex vivo disease models and pancreatic sections from human organ donors with diabetes have linked changes in $\beta$ cell mass and function with the activation of a variety of $\beta$ cell stress pathways that are thought to both accelerate $\beta$ cell death and increase $\beta$ cell immunogenicity (5-11).

At present, longitudinal imaging of the $\beta$ cell compartment and sampling of the pancreas in living individuals is not clinically feasible. Studies performed using isolated islets or pancreatic sections from organ donors with diabetes provide critical information about disease pathogenesis but enable only a single snapshot view of disease pathogenesis. Improved temporal resolution of the molecular programs modulated within the pancreatic $\beta$ cell during T1D evolution has the potential to inform therapeutic and biomarker strategies in humans (12-14), underscoring the need to interrogate alternative model systems.

In this regard, the non-obese diabetic (NOD) mouse has been used to study T1D pathogenesis for over three decades (15-17). Islets in NOD mice show evidence of immune cell infiltration as early as four weeks of age (18), and approximately $60-80 \%$ of 
female NOD mice develop diabetes by $16-20$ weeks of age $(15,19)$. Consistent with patterns observed in humans, $\beta$ cell function and mass decline during the pre-diabetes phase. In cross-sectional analyses, subsets of overlapping stress pathways have been identified in $\beta$ cells from NOD mice and in human islets from organ donors with diabetes $(16,20,21)$. To gain additional insight into the time course of molecular changes in the $\beta$ cell during T1D progression, we used a data independent acquisition-mass spectrometry (DIA-MS) based approach to monitor longitudinal changes in the islet cell proteome during early and late disease progression in NOD mice. In parallel, we compared proteomic signatures in islets from diabetic NOD mice with those observed in islets from NOD-SCID mice rendered acutely diabetic by the adoptive transfer of T cells from NODBDC2.5 mice. Finally, to gain insight into potentially protective pathways, proteomes generated from NOD mouse islets at the time of diabetes onset were compared with those from NOD mice that remained diabetes-free through $46-48$ weeks of age. Key findings were validated using immunofluorescence in pancreatic tissue sections. To illustrate the utility of this approach in prioritizing $\beta$ cell proteins as T1D biomarkers, we focused on protein disulfide isomerase A1 (PDIA1) as an example of a secreted protein that was found to be differentially expressed in NOD islets during diabetes progression. PDIA1 was selected as a target for the development of a high-sensitivity electrochemiluminescence assay using MesoScale Discovery technology. Using this assay, we demonstrated increased $\beta$ cell expression and circulating concentrations of PDIA1 in plasma from NOD mice during the evolution of T1D and in the serum of children with recent-onset T1D compared to age and sex-matched pediatric controls. 


\section{Results}

\section{Analysis of temporal changes in the NOD proteome during disease progression}

To characterize temporal changes in islet protein expression during diabetes progression, pancreatic islets were isolated from age-matched CD1 and NOD mice at 10,12 , and 14 weeks of age and at the time of diabetes onset (mean age of diabetes development $17 \pm 3.3$ weeks; mean \pm S.D.) and analyzed using LC MS/MS (Figure 1). An average of 1160 proteins and an average of 897 overlapping proteins were quantified in NOD and CD1 mouse islets (Supplementary Figure 1). Since CD1 mice are not diabetes-prone and exhibit tightly regulated blood glucose levels, we used sex and age-matched CD1 mice to normalize protein abundance in NOD islets. To identify differentially expressed proteins at each time point, results were analyzed using median normalization and a filtering criterion of a 1.5 -fold change in protein abundance.

In principal component analysis (PCA), NOD mice at different pre-diabetic ages $(10,12$, and 14 weeks) clustered primarily as one group, whereas diabetic mice were distinctly clustered (Figure 2A). Unsupervised hierarchical clustering analysis of the top 30 differentially expressed (DE) islet proteins revealed notable changes in the temporal expression of several proteins during diabetes progression (Figure 2B). As expected, there was a time-dependent loss of insulin and islet amyloid polypeptide (IAPP) expression. Interestingly, we observed a time-restricted upregulation of several proteins implicated in stress mediation and the maintenance of normal $\beta$ cell function during the prediabetic phase. Proteins exhibiting this pattern of expression included actin-related protein 2/3 complex 2 (ARPC2), which regulates actin cytoskeleton-mediated transport of secretory vesicles (22-24), collagen 1A1 (COL1A1), and collagen 1A2 (COL1A2), 
which are extracellular matrix proteins $(25,26)$, and the metallothioneins MT1 and MT2, which have been linked with suppression of immune responses $(27,28)$. A similar pattern was observed for peroxiredoxin 3 (PRDX3), a protein that has been linked with the regulation of mitochondrial function, and 14-3-3b, which plays a role in a number of metabolic processes, including mTOR signaling, amino acid metabolism, and mitochondrial function (29,30). Protein disulfide isomerase A1 (PDIA1) was upregulated similarly during weeks 12 to 14 . Notably, PDIA1 is a thiol reductase that plays a critical role in proinsulin folding and regulation of ER function (31). Overall, this pattern of upregulation was observed through the 14-week timepoint followed by a declining pattern expression of several of these proteins with potentially protective roles that heralded diabetes development (Figure 2B).

Figure $3 \mathbf{A}$ shows the top 10 upregulated pathways, while Figure 3B shows the top 10 downregulated pathways in longitudinal analysis of islets from NOD mice using ingenuity pathway analysis. During diabetes progression, pathways related to Cdc42, integrin signaling, actin, epithelial adherens, and mTOR signaling were all upregulated (Figure 3A). EIF2 signaling, which is involved in global mRNA translation initiation and is a target during the unfolded protein response and ER stress $(32,33)$, was markedly upregulated at weeks 12 and 14 and in diabetic mice (Figure 3A), and changes in mitochondrial function were represented in both up-and down-regulated pathways. Significantly downregulated pathways encompassed several metabolic pathways, including the TCA cycle, oxidative phosphorylation, fatty acid oxidation, and glutathione redox reactions. Sirtuin signaling and phagosome maturation were also downregulated (Figure 3B and Supplementary Figures 2 and 3). 


\section{Comparison of spontaneous and induced models of immune cell infiltration}

To identify commonalities and differences in the islet proteome between the chronic, spontaneous NOD model and an aggressive, acute model of immune-mediated $\beta$ cell destruction, we compared proteomics results from islets isolated from diabetic NOD mice and islets isolated at the time of diabetes development from NOD-SCID mice that had undergone adoptive transfer of CD4+ T-cells from NOD.BDC2.5 mice. Mice in the latter group develop significant hyperglycemia around 7 days following adoptive transfer. Despite this difference in the time-course of diabetes development compared to the chronic and slowly progressive NOD model, approximately $\sim 65 \%$ of identified proteins were common to both models (Figure 4A). In addition, a comparison of functional canonical pathways suggested that similar pathways were activated in both models. Key overlapping pathways included modulation of EIF2 signaling and the unfolded protein response, mitochondrial dysfunction, oxidative phosphorylation, and mTOR signaling (Figure 4B). These results suggest that irrespective of the type of inflammation (acute or chronic), similar patterns of $\beta$ cell stress are activated, underscoring the importance of this core set of pathways in T1D pathogenesis.

\section{Proteome comparison of NOD mice that developed diabetes and that remaining diabetes-free}

We reasoned that comparing diabetic NOD mice and NOD mice that remained diabetes-free through extended follow-up might highlight protective pathways within the $\beta$ cell during immune activation. Therefore, proteomic analysis was performed on islets from 46-48 wk old NOD mice who remained diabetes-free, and results were compared to 
islets collected from NOD mice at the time of diabetes development. Principal component analysis indicated a clear separation between the diabetes-resistant group and diabetic NOD mice (Figure 5A). Next, unsupervised hierarchical clustering analysis was performed using the Euclidian distance and average linkage method (Figure 5B). Data from this analysis revealed upregulation of several unique proteins previously linked with the mitigation of $\beta$ cell stress and maintenance of normal $\beta$ cell function in the diabetesresistant NOD mice. Among the top proteins upregulated in diabetes resistant mice and down-regulated in diabetic mice were IAPP and antioxidant-1 (ATOX1), a copper chaperone shown to be protective against hydrogen peroxide and superoxide mediatedoxidative stress (34). Other key proteins showing this pattern of expression were proteasome subunit beta 10 (PSB10), which is involved in the maintenance of protein homeostasis (35), coactosin like protein (COTL1), an F-actin-binding protein that plays a role in cellular growth (36); and S100A4, which functions as an intracellular cytosolic calcium sensor $(37,38)$.

Pathway enrichment analysis was performed to uncover the signaling pathways that were differentially regulated between these two groups. Figure $\mathbf{5 C}$ shows the top 10 significantly upregulated pathways in diabetes-resistant NOD mice compared to diabetic NOD mice. The size of each circle indicates the number of proteins enriched in each pathway, and the density of each circle represents their p-values. In diabetes-resistant NOD mice, there was a notable modulation of pathways involved in maintaining cellular homeostasis, tissue repair, tissue clearance (i.e., phagocytosis in macrophages and monocytes), and aryl hydrocarbon receptor signaling, which has been linked with the mitigation of insulitis in NOD mice. (39). In line with this, we observed downregulation of 
pathways related to mitochondrial dysfunction, phagosome maturation, oxidative phosphorylation, and the unfolded protein response (Figure 5D). Interestingly, actin cytoskeleton signaling and epithelial adherens junction signaling were identified as being among both the up-and down-regulated pathways, with distinct proteins implicated within the up-and down-regulated categories.

\section{Validation of protein targets by immunofluorescence and electro- chemiluminescence}

To validate key findings from the proteomic analysis, immunofluorescence staining of pancreatic tissue sections was performed using a separate cohort of NOD mice aged 9 to 13 weeks and at diabetes onset. Three protein targets, PDIA1, 14-3-3b, and PRDX3, were selected for validation experiments based on top hits from the analysis shown in Figure 2B and their known roles in maintaining $\beta$ cell function $(30,31,40,41)$. Consistent with proteomics data, the staining intensity of islet PDIA1 (Figure 6A) and 14-3-3b increased from 9-13 weeks in NOD mice, followed by a significant loss of target protein expression at T1D onset (Figure 6B). Changes in the staining intensity of PRDX3 did not reach change significantly during the prediabetic timepoints (Figure 6C). However, we observed a significant decrease in PRDX3 at T1D onset in NOD mice.

\section{Analysis of circulating PDIA1 as a T1D associated biomarker}

In addition to its intracellular role as a thiol reductase $(31,42,43)$, PDIA1 is known to be a secreted protein (31). At present, circulating biomarkers that reflect the health of the $\beta$ cell are lacking. Therefore, to determine whether the islet-specific upregulation of 
PDIA1 identified in the proteomics and immunofluorescence analyses was linked with changes in circulating PDIA1 levels and to test its utility as a biomarker of $\beta$ cell stress in T1D, we developed a high-sensitivity electrochemiluminescence assay using Meso Scale Discovery technology. PDIA1 was measured using serially diluted (1:4) recombinant PDIA1, and this analysis showed that PDIA1 could be detected in the range of 0.152 $\mathrm{ng} / \mathrm{ml}$ up to $2500 \mathrm{ng} / \mathrm{ml}$ (Figure 7A). Using plasma collected from the same mice employed in the longitudinal proteomics analysis shown in Figure 2, we found that the plasma levels of PDIA1 were significantly increased in pre-diabetic NOD mice compared to CD1 mice at 10 and 14 weeks of age (Figure 7B-D). However, PDIA1 levels were not different between NOD mice at the time of diabetes onset and age-matched CD1 mice (Figure 7E). In addition, PDIA1 levels were below the detectable range in plasma from diabetic NOD-SCID mice that had undergone T-cell adoptive transfer.

Next, we applied this assay to serum samples collected from children within 48 hours of the clinical onset of T1D $(n=10$; average age $($ mean $\pm S D)=11.57 \pm 4.05 \mathrm{yrs} ; 6$ male; 4 female) and in serum collected from non-diabetic pediatric controls $(n=13$; average age $=12.1 \pm 4.20 ; 7$ male; 6 female). Interestingly, serum levels of PDIA1 were significantly higher in pediatric subjects with recent-onset T1D compared to controls, suggesting PDIA1 may have utility as a clinical, human T1D biomarker. (Figure 7F). 


\section{Discussion}

In this study, we aimed to identify temporal changes in islet $\beta$ cell protein expression during the evolution of T1D using three distinct mouse models of T1D and high-throughput DIA-MS-based proteomics. We analyzed the proteome of islets collected from female NOD mice at three pre-diabetic time points and the time of diabetes onset and compared protein abundance with sex- and age-matched non-diabetic CD1 mice. To compare chronic and acute models of T1D, we analyzed the proteome of islets from diabetic NOD mice and NOD-SCID mice that has been rendered acutely diabetic following the adoptive transfer of $\mathrm{T}$ cells from NOD.BDC2.5 mice. To gain insight into potential mechanisms that contribute to $\beta$ cell resiliency in the face of immune activation, we compared the islet proteomes of NOD mice at diabetes onset to NOD mice that remained diabetes-free after $46-48$ weeks of observation. Finally, to illustrate the utility of this approach in prioritizing $\beta$ cell proteins as T1D biomarkers in humans, we focused on protein disulfide isomerase A1 (PDIA1) as one example of a secreted protein that was differentially expressed in NOD islets during diabetes progression for the development of a high-sensitivity electrochemiluminescence assay to be employed in serum and plasma.

Proteomics analysis of the three mouse models revealed several notable themes. In the dataset obtained from the longitudinal NOD cohort, we observed an early but timerestricted increase in the expression of several proteins previously linked with secretory function, proinsulin folding, and stress mitigation, including proteins known to be involved in the mitigation of endoplasmic reticulum and oxidative stress. Interestingly, we observed week 14 (44) as a potential inflection point, where the loss of expression of these protective proteins heralded T1D onset. Consistent with this, canonical pathway analysis 
of differentially expressed proteins from wks 10, 12, and 14 and diabetes onset identified upregulation of pathways associated with defective insulin synthesis and several $\beta$ cell stress pathways, including mitochondrial dysfunction, ER stress, and UPR activation. We observed also a downregulation of signaling pathways that were crucial for the mitigation of ongoing cellular stress, including glutathione redox signaling, which is known to counteract the effects of reactive oxygen species $(45,46)$ and phagosome maturation, which is involved in the clearing of cellular debris $(47,48)$.

This biphasic pattern is reminiscent of metabolic data from natural history cohorts of autoantibody-positive individuals who progress to T1D, where there are compensatory changes in the architecture of insulin secretion that largely maintain glycemia until $\sim 12$ months prior to disease onset, followed by marked loss of insulin secretion and rapidly worsening glycemic control until diabetes diagnosis (1). Our findings are also consistent with cross-sectional studies that have analyzed gene and protein expression patterns in pancreatic sections from human donors with diabetes (49-52) and in previous studies in mouse models of diabetes, where a prominent role for ER and mitochondrial dysfunction has been identified during disease progression $(6,10,53,54)$. Notably, we found these pathways are activated early in the disease process, and there is continued overlap between several of these key activated stress pathways in the NOD mouse model and in the acute, inducible model of T1D at the time of diabetes onset. While the former is a spontaneous model and the latter is an acute model of islet destruction, similarities between the proteomic analysis of these two models highlight the importance of this core set of pathways in T1D pathogenesis. 
To validate selected findings from the proteomics analysis, we performed immunofluorescence experiments, focusing on three targets identified in the longitudinal NOD cohort: 14-3-3 $\beta$, PRDX3, and PDIA1. Members of the 14-3-3 protein family have been implicated in various metabolic signaling pathways and have been linked with protection against apoptosis in pancreatic $\beta$ cells (30). PRDX3 prevents mitochondrial dysfunction, and its overexpression has been shown to be protective against oxidative stress induced by insulin resistance and hyperglycemia $(40,55)$. PDIA1 is a highly abundant ER localized thiol oxidoreductase that has been implicated in glucosestimulated insulin secretion, proinsulin processing, and protection against ER stress (31).

Of note, PDIA1 has been described as a secreted protein, and in other cell types, PDIA1 release is increased in the setting of injury and stress $(56,57)$. Extracellular PDIA1 has been linked with the regulation of thrombus formation during vascular inflammation $(58,59)$, but a complete understanding of the extracellular role of this protein is lacking. Interestingly, anti-PDIA1 antibodies have been identified in patients with recent-onset T1D (60), suggesting that $\beta$ cell derived PDIA1 serves as a T1D autoantigen. Against this background, we hypothesized that increased $\beta$ cell expression of PDIA1 may be reflected in the circulation and that measurement of PDIA1 may have utility as a T1D biomarker. To test this possibility, we developed a high sensitivity electrochemiluminescence assay to measure serum and plasma PDIA1. Using this assay, we documented an increase in plasma PDIA1 in pre-diabetic NOD mice and in the serum of children with recent-onset T1D. To our knowledge, this represents the first assessment of circulating PDIA1 in individuals with diabetes. 
Our study has several limitations that should be acknowledged. First, there are significant differences between mouse models of T1D and human T1D (61-63), underscoring the need to cross-validate findings from mouse models in human samples. We followed such a workflow and strategy with PDIA1 and documented increased serum levels of PDIA1 in a small cohort of pediatric subjects with recent-onset T1D. While biomarkers with the ability to non-invasively monitor $\beta$ cell stress are notably lacking in T1D, it is important to acknowledge that ours is a small cross-sectional study and validation in larger cohorts should be performed. Whether PDIA1 is purely a marker of $\beta$ cell stress or may reflect $\beta$ cell mass changes is not clear from our study and should be tested in follow-up. Along these lines, it will be essential to test PDIA1 levels in samples collected from clinical cohorts followed longitudinally during T1D progression. Such an analysis will provide necessary insight into whether PDIA1 can predict T1D risk. It is interesting that PDIA1 levels were higher in children with new onset T1D, whereas plasma elevations in PDIA1 were most notable at pre-diabetic timepoints in NOD mice. This is consistent with more recent data showing that there is substantial $\beta$ cell mass remaining in humans at T1D onset $((64,65)$, whereas in both of the mouse models studied here, $\beta$ cells are nearly completely destroyed by the time of diabetes onset $(66,67)$..

Notwithstanding these limitations, our study highlights the value of unbiased proteomics approaches for identifying key $\beta$ cell pathways involved in the temporal evolution of T1D. Utilizing this strategy, we identified a common set of modulated pathways across several distinct mouse models of T1D and identified PDIA1 as a potential T1D associated biomarker. 


\section{Materials and Methods}

\section{Animals and experimental procedures}

Female NOD/ShiLTJ (NOD), NOD-BDC2.5 and NOD-SCID mice were purchased from the Jackson Laboratory. Female outbred CD1 mice were purchased from Charles River Laboratories. Mice were maintained at the Indiana University School of Medicine Laboratory Animal Resource Center under pathogen-free conditions and protocols approved by the Indiana University Institutional Animal Care and Use Committee.

Mice were allowed to be acclimated for at least two weeks upon arrival and before the initiation of experiments. Pancreatic islets were isolated at the indicated time points, or the pancreas was harvested at the indicated time points, as described previously $(68,69)$. Islets were hand-picked, washed twice with PBS, and stored as pellets at $-80^{\circ} \mathrm{C}$ until use. Blood destined for plasma analysis was obtained at the time of euthanasia via cardiac puncture, transferred to a Becton Dickinson Vacutainer K2EDTA tube (Cat\# 365974 ), and centrifuged at $5,000 \mathrm{rpm}$ for 10 minutes at $4^{\circ} \mathrm{C}$. The separated plasma samples were aliquoted into $1.5 \mathrm{ml}$ cryotubes and stored at $-80^{\circ} \mathrm{C}$ until use.

Single-cell splenocyte suspensions were prepared for adoptive transfer experiments from 12-week-old male NOD-BDC2.5 mice, as previously described (70). CD4+ T cells were purified by negative selection (Cat\# 558131, BD Biosciences), activated in 6 -well plates $\left(5 \times 10^{6}\right.$ cells/well), coated with anti-CD3 and anti-CD28 antibody ( $1 \mathrm{mg} / \mathrm{mL}$ each), and expanded for $72 \mathrm{~h}$ in T-75 flasks $\left(5 \times 10^{6}\right.$ cells/flask $)$ in complete RPMI 1640 medium (1\% penicillin/streptomycin and 10\% FBS) containing $100 \mathrm{U} / \mathrm{mL}$ IL-

2. Cells were subsequently collected, washed twice with Hanks' balanced salt solution (HBSS), and diluted to $5 \times 10^{6}$ cells $/ \mathrm{mL}$ in HBSS (71). Recipient 8-week-old 
immunodeficient male NOD-SCID mice received $1 \times 10^{6} \mathrm{~T}$ cells via intraperitoneal injection, and blood glucose was measured daily for 21 days. Age-matched NOD-SCID mice that received HBSS alone were used as controls. The onset of diabetes was defined as two consecutive blood glucose readings of $\geq 275 \mathrm{mg} / \mathrm{dL}$.

\section{Mass Spectrometry sample processing}

Islet pellets were lysed and denatured by adding $48 \mathrm{mg}$ of urea to $\sim 100 \mu \mathrm{L}$ of pelleted cells. Lysates were ultrasonicated with 5 successive 10 s pulses to ensure complete lysis and to shear DNA. Protein content was measured by BCA assay, (Pierce) and $50 \mu \mathrm{g}$ of protein was transferred to a 1.5-mL tube and the volume was adjusted to $250 \mu \mathrm{L}$ using $50 \mathrm{mM}$ ammonium bicarbonate ( $\mathrm{pH}$ 8.0). Sample were subsequently reduced with $25 \mathrm{mM}$ of freshly prepared tris(2-carboxyethyl) phosphine at $37^{\circ} \mathrm{C}$ for 40 min, alkylated with $10 \mathrm{mM}$ of freshly prepared iodoacetamide for $40 \mathrm{~min}$ at room temperature in the dark, and diluted to $800 \mu \mathrm{L}$ with $50 \mathrm{mM}$ ammonium bicarbonate. The $\mathrm{pH}$ of the sample was adjusted to 8.0 , and digested using a 50:1 ratio of protein:trypsin (Sequence grade, Promega) at $37^{\circ} \mathrm{C}$ overnight in the presence of $10 \%$ acetonitrile with constant agitation, using trypsin at a 50:1 ratio. The digest was then acidified with $10 \%$ Formic Acid ( $\mathrm{pH} 2-3$ ), desalted on a 96-well microelution plate (Oasis HLA, Waters), and dried before mass spectrometry (MS) analysis.

\section{Data-independent acquisition LC-MS/MS analysis}

Discovery proteomics was performed by liquid chromatography-tandem mass spectrometry (LC-MS/MS) using an Eksigent 415 HPLC system equipped with an 
Ekspert nanoLC 400 autosamplers coupled to a SCIEX 6600 TripleTOF mass spectrometer (SCIEX, Framingham, MA) operated in data-independent acquisition (DIA) mode. Two microgram of peptides were injected onto a ChipLC trap-elute system

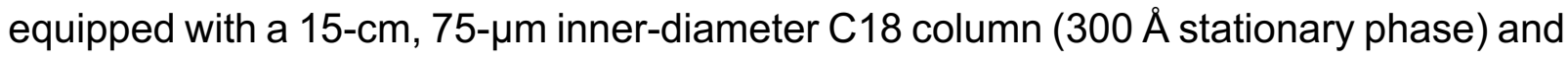
separated at a flow rate of $500 \mathrm{~nL} / \mathrm{min}$ using a linear $A B$ gradient of $3-35 \%$ solvent $B$ (0.1\% FA in acetonitrile) for $60 \mathrm{~min}, 35-85 \% \mathrm{~B}$ for $2 \mathrm{~min}$, hold at $85 \%$ B for $5 \mathrm{~min}$, and re-equilibration at 3\% B for 7 min. Mass spectra were obtained with 64 variable-width precursor isolation windows. Dwell-times in MS1 and MS/MS were 250 and $45 \mathrm{ms,}$ respectively, for a total cycle time of $3.2 \mathrm{~s}$. The collision energy was optimized for an ion $\mathrm{m} / \mathrm{z}$ centered on the isolation window, with the collision energy spread ranging from 515. Source gas 1 was set to 3 , gas 2 was set to 0 , curtain gas was set to 25 , source temperature was set to $100^{\circ} \mathrm{C}$, and source voltage was set to $2400 \mathrm{~V}$.

\section{Post-acquisition analysis}

Peptide library generation. Individually acquired DIA files were processed using the Signal Extraction module of the DIA-Umpire software tool (DIAu-SE). A protein sequence database was built by concatenating the target SwissProt mouse proteome database (canonical sequences), Biognosys iRT peptides for retention time alignment (Biognosys, Schlieren, Switzerland), and a random decoy sequence database with the same size as the target database for false discovery rate (FDR) estimation. Pseudospectra generated in the DIAu-SE step were then searched against the concatenated database for peptide identification. Identified peptides filtered with a $1 \%$ peptide-level FDR were used for library generation. 
Quantitation of individual specimen DIA-MS files. Raw intensity data for peptide fragments were extracted from DIA files using the open-source openSWATH workflow against the sample-specific peptide spectral library described above. Briefly, peptide assay peak groups were extracted from raw DIA files and scored against the peptideand decoy-spectral libraries with the same size based on a composite of 11 data-quality subscores. Target peptides with a 1\% FDR were included for downstream analyses.

Curating files for quality. All files were individually curated prior to protein-level roll-up and subsequent quantitation. The following parameters were considered: total ion chromatogram profile and intensity, file quality within the library build (Q1, Q2, Q3 data distribution from DIAumpire), and raw distribution of proteins compared to decoys derived in openSWATH. Files exhibiting aberrant or low-quality results for any of these parameters were excluded from subsequent analysis steps. All steps were performed while blinded to filenames or experimental group.

Data normalization, protein-level roll-up, and statistical analyses. The total ion current associated with the MS2 signal across the chromatogram was calculated for normalization, excluding the last $15 \mathrm{~min}$ to avoid including the signal from contaminants/noise. This 'MS2 signal' of each file, akin to a total protein load stain on a Western blot gel, was used to adjust each transition intensity of each peptide in the corresponding file. Normalized transition-level data were then processed using mapDIA software to remove noisy/interference transitions from the peptide peak groups, 
calculate peptide and protein level intensities, and perform pairwise comparisons between groups.

The following pairwise comparisons were made: NOD vs. CD1 for each time point (weeks 10, 12, and 14); NOD-BDC2.5 vs. NOD-SCID ctrl; NOD resistant vs. NOD mice with diabetes. The mapDIA tool generated a q-value to indicate an FDR rather than a simple p-value. We assumed that protein expression differs significantly between two groups when the $\log _{2}$ (fold-change) was $>0.6$ (i.e., $\sim 1.5$ fold-change) and q-value/FDR was $<0.01$.

\section{Immunofluorescence staining and quantification}

Immunofluorescence (IF) was performed to validate key findings from the MS analysis. Briefly, formalin-fixed paraffin-embedded (FFPE) pancreatic tissues from an independent cohort of pre-diabetic age-matched NOD and CD1 mice, obtained at 7, 9, 11 , and 13 weeks of age, were sectioned at a thickness of $5 \mu \mathrm{m}$ and deparaffinized. The sections were hydrated twice with fresh Xylene for 5 minutes and a series of decreasing ethanol concentration (100 to $70 \%$ ). Antigen retrieval was performed using citrate buffer and stained using antibodies against PDIA1 (Cell Signaling, Cat\# 3501S), PRDX3 (Abcam, Cat\# ab73349), 14-3-3B/YWHAB (Sigma, Cat\# HPA011212), insulin (Dako, Cat\# IR002), and glucagon (Abcam, Cat\# ab10988). Secondary antibodies included Alexa 488-labeled goat anti-guinea pig, Alexa 568-labeled donkey anti-rabbit, and Alexa 647-labeled donkey anti-mouse antibodies. Nuclei were stained with DAPI. Images were acquired using LSM800 confocal microscope (Zeiss, Germany) and quantified using image-J software (NIH) as described previously (69). From each animal, 3-7 islets were 
randomly selected for imaging. Normalized total islet cell fluorescence intensity was calculated independently by two individuals working in a blinded fashion.

\section{Collection of human serum samples}

Fasting serum was obtained from children with recent-onset T1D and age- and sex-matched non-diabetic healthy controls under protocols approved by the Indiana University Institutional Review Board. Written informed consent or parental consent and child assent were obtained from all participants (72). Children with T1D had been newly diagnosed within 48 hours of blood collection and were hospitalized at the Riley Hospital for Children. Control pediatric subjects were ambulatory, did not take any chronic prescription medications, and were free of any chronic or acute illness within two weeks preceding sampling.

\section{Measurement of serum PDIA1}

Assay development

To measure circulating levels of PDIA1, we developed a high-sensitivity electrochemiluminescence assay using the Meso Scale Discovery (MSD) ELISA conversion kit (Cat\# K15A01-1), according to the manufacturer's instructions. Briefly, five anti-P4HB/PDIA1 antibodies were purchased from multiple vendors (Table 2) and screened for their ability to bind human recombinant PDIA1 protein (rPDIA1). The day before the experiment, single spot standard plates of the conversion kit were washed three times with $150 \mu \mathrm{L}$ of PBS and incubated overnight with $30 \mu \mathrm{L}$ of each antibody in PBS at $4^{\circ} \mathrm{C}(73,74)$. The following day, the antibodies were washed with $0.05 \%$ PBSTween 20 (PBS-T) and blocked with 1\% of blocking buffer A (Cat\# R93BA-1) for $1 \mathrm{hr}$ in 
an orbital shaker at 700rpm. A 4-fold serial dilution of rPDIA1 was prepared with a starting concentration of $2500 \mathrm{ng} / \mathrm{mL}$, which was added to the plates and incubated in an orbital shaker for $1 \mathrm{hr}$ at RT. Then, the plates were washed three times with $0.05 \%$ PBS-T and incubated with a PDIA1 detection antibody generated from different species (for example, mouse capture antibody was used with rabbit detection antibody) to prevent crossreactivity and in an orbital shaker for $1 \mathrm{hr}$. Subsequently, the plates were washed three times with $0.05 \%$ PBS-T and incubated with species-specific Sulfo-Tag for $1 \mathrm{hr}$ in an orbital shaker. Next, the plates were washed three times with $0.05 \%$ PBS-T, $150 \mu \mathrm{L}$ of 1X read-buffer (Cat \# R92TC-2) was added to each well, and the signal was detected immediately using a MESO QuickPlex SQ 120 plate reader (MSD). Data were analyzed using Discovery Workbench software version 4.0.

\section{Validation in serum and plasma samples}

Thirty $\mu \mathrm{L}$ of 2-fold diluted mouse plasma samples or thirty microliters of 4-fold diluted human serum samples were assayed, while 4-fold serially diluted rPDIA1 protein with a starting concentration of $2500 \mathrm{ng} / \mathrm{mL}$ was used to generate a standard curve. To quantitate circulating levels of PDIA1 in human serum and mouse plasma samples, standard one spot MSD plates were incubated with $5 \mu \mathrm{g} / \mathrm{mL}$ of capture antibody (Cat\# HPA018884; Sigma) overnight at $4^{\circ} \mathrm{C}$, and the same procedures described above under "Assay development" were followed. Following sample incubation, plates were washed as described above and incubated with mouse PDIA1 detection antibody (Cat\# MA3-019; Thermo Fisher Scientific) for $1 \mathrm{hr}$ in an orbital shaker at (RT). The plates were then washed and incubated with an MSD mouse Sulfo-Tag for $1 \mathrm{hr}$ at RT in a shaker. Finally, 
the plates were read using $150 \mu \mathrm{L}$ of read-buffer in a Quick Plex SQ 120 plate reader (MSD), and the data were analyzed as described above.

\section{Statistical analysis}

Statistical analysis of the proteomics data is detailed above. Other experimental data were analyzed using GraphPad Prism version 9. Statistical significance of the difference between two groups was determined using the Student's t-test and between more than two groups by one-way ANOVA; $p \leq 0.05$ was considered significant. Data are presented as mean \pm S.E.M or mean \pm S.D. Temporal changes in islet proteomics were analyzed using principal component analysis (PCA). Differentially expressed proteins were identified using unsupervised hierarchical clustering analysis and visualized using $\begin{array}{lll}\text { heatmap (https://software.broadinstitute.org/morpheus/). } & \text { The }\end{array}$ upregulated/downregulated pathways were recognized using pathway enrichment and the Ingenuity pathway analysis. 
Figure Legends:

Figure 1: Schematic representation of study design and experimental workflow (created using BioRender.com)

Figure 2: Proteomic analysis of pancreatic islets in NOD and CD1 mice over time. (A) Principal component analysis (PCA) of all quantified islet proteins from NOD and CD1 mice at 10,12, and 14 weeks of age and during diabetes onset indicates the reproducibility of biological replicates. (B) Unsupervised hierarchical clustering analysis of the top 30 differentially expressed proteins in NOD when compared to age and sexmatched CD1 mice from 10,12, and 14 weeks of age, and during diabetes onset. ( $n=3-$ 12 animals/ group)

Figure 3: Ingenuity pathway analysis of islet proteome. The top 10 upregulated (A) and downregulated $(\mathrm{B})$ canonical pathways modulated during diabetes progression in islets collected from NOD mice compared to age-matched CD1 mice.

Figure 4: Comparison of the islet proteome between acute and chronic models of T1D. (A) Venn diagram showing protein overlap between the spontaneous and inducible models of T1D. (B) Pathway enrichment analysis identified common pathways that are significantly activated during the pathogenesis of T1D.

Figure 5: Proteomics analysis of diabetes-resistant NOD mice and NOD mice that developed diabetes. (A) Principal component analysis (PCA) of the islet proteome in NOD mice that remained diabetes-free through 46-48 wks of age (Res) and NOD mice at 
the time of the development of diabetes (Dev). (B) Heatmap showing top differentially expressed islet proteins in diabetes-resistant mice and mice at the time of diabetes onset. Shown are up-regulated (C), and down-regulated (D) pathways (y-axis) and the corresponding number of proteins (x-axis) differentially expressed in islets from diabetesresistant mice.

Figure 6: Immunofluorescence-based validation of protein targets in NOD mice. (AC) Pancreas sections from 9, 11, and 13 wk old NOD mice and in NOD mice that developed diabetes were immunostained for PDIA1 (A), 14-3-3b (B), and PRDX3 (C) (red), and costained with insulin (green) and glucagon (white). Scale bar $=10$ um. The bar graphs show the quantitation of fluorescence intensity for each protein target calculated using the corrected total islet cell fluorescence. ( $N=4-5$ mice/age-group; 5-10 islets/mice were used for quantification; ${ }^{*} \mathrm{P}<0.05,{ }^{* *} \mathrm{P}<0.001$ )

Figure 7: PDIA is increased in pre-diabetic NOD mice and in recent-onset T1D. (A) Standard curve generated using a serial dilution of recombinant PDIA1 protein showing higher and lower detection limits of assay sensitivity. (B-E) Measurement of circulating PDIA1 in plasma samples of sex and age-matched CD1 and NOD mice at different ages. $\mathrm{N}=4$-7 mice/group, ${ }^{*} \mathrm{P}<0.05,{ }^{* *} \mathrm{P}<0.001$. (F) Plasma concentration of PDIA1 in nondiabetic control subjects ( $n=10$, average age $12 \pm 4.2$ yrs) and pediatric subjects with recent-onset T1D ( $n=14$, average age $11.57 \pm 4.05$ yrs $){ }^{* *} P=0.001$ 


\section{Contributors}

FS and CEM conceived and designed the study. FS and RNB performed experiments.

KR and J.V. prepared and ran LC-MS/MS samples. DS, XL, HW, and PK performed computational analyses. FS and CEM interpreted the data and wrote the manuscript. All authors provided critical revisions and edits to the manuscript. All authors approved the final manuscript. CEM is the guarantor of this work.

\section{Data Sharing Statement.}

Data presented as part of this manuscript are available from the corresponding author upon request.

\section{Declaration of Competing Interest}

CEM and FS have filed a provisional patent application for the use of PDIA1 as a diabetes biomarker. No potential conflicts of interest were disclosed by other authors.

\section{Funding and Acknowledgements}

This work was supported by NIH grants R01 DK093954 and DK127308(to CEM) and U01DK127786 and UC4 DK 104166 (to RGM and CEM), VA Merit Award I01BX001733 (to CEM), 2-SRA-2019-834-S-B, JDRF 2-SRA-2018-493-A-B (to CEM and RGM), and gifts from the Sigma Beta Sorority, the Ball Brothers Foundation, and the George and Frances Ball Foundation (to CEM). F.S. was supported by JDRF postdoctoral fellowship (3-PDF-20016-199-A-N). The authors acknowledge the support of the Islet and Physiology Core and the Translation Core of the Indiana Diabetes Research Center (P30DK097512). We thank Dr. Emily Anderson-Baucum and Dr. Jan Kajstura for their assistance in editing the text of this manuscript. 


\section{REFERENCES}

1. Evans-Molina C, Sims EK, DiMeglio LA, Ismail HM, Steck AK, Palmer JP, et al. $\beta$ Cell dysfunction exists more than 5 years before type 1 diabetes diagnosis. JCI Insight. 2018 Aug 9;3(15):120877.

2. Butler AE, Galasso R, Meier JJ, Basu R, Rizza RA, Butler PC. Modestly increased beta cell apoptosis but no increased beta cell replication in recent-onset type 1 diabetic patients who died of diabetic ketoacidosis. Diabetologia. 2007 Nov 1;50(11):2323-31.

3. Atkinson MA, Eisenbarth GS, Michels AW. Type 1 diabetes. Lancet. 2014 Jan 4;383(9911):69-82.

4. Gepts W. Pathologic Anatomy of the Pancreas in Juvenile Diabetes Mellitus. Diabetes. 1965 Oct 1;14(10):619-33.

5. Brozzi F, Eizirik DL. ER stress and the decline and fall of pancreatic beta cells in type 1 diabetes. Upsala Journal of Medical Sciences. 2016 Apr 2;121(2):133-9.

6. Chen J, Stimpson SE, Fernandez-Bueno GA, Mathews CE. Mitochondrial Reactive Oxygen Species and Type 1 Diabetes. Antioxid Redox Signal. 2018 Nov 10;29(14):1361-72.

7. Cnop M, Welsh N, Jonas J-C, Jörns A, Lenzen S, Eizirik DL. Mechanisms of pancreatic betacell death in type 1 and type 2 diabetes: many differences, few similarities. Diabetes. 2005 Dec;54 Suppl 2:S97-107.

8. Engin F, Yermalovich A, Nguyen T, Hummasti S, Fu W, Eizirik DL, et al. Restoration of the Unfolded Protein Response in Pancreatic $\beta$ Cells Protects Mice Against Type 1 Diabetes. Sci Transl Med. 2013 Nov 13;5(211):211ra156.

9. Sobhi W. Involvement of Oxidative Stress in Type 1 Diabetes. AJBSR. 2020 Jan 17;6(6):53843.

10. Tersey SA, Nishiki Y, Templin AT, Cabrera SM, Stull ND, Colvin SC, et al. Islet $\beta$-Cell Endoplasmic Reticulum Stress Precedes the Onset of Type 1 Diabetes in the Nonobese Diabetic Mouse Model. Diabetes. 2012 Apr;61(4):818-27.

11. Santos AS, Cunha Neto E, Fukui RT, Ferreira LRP, Silva MER. Increased Expression of Circulating microRNA 101-3p in Type 1 Diabetes Patients: New Insights Into miRNARegulated Pathophysiological Pathways for Type 1 Diabetes. Frontiers in Immunology. 2019;10:1637.

12. Evans-Molina C, Hatanaka M, Mirmira RG. Lost in Translation: ER Stress and the Decline of $\beta$-cell Health in Diabetes Mellitus. Diabetes Obes Metab. 2013 Sep;15(0 3):159-69. 
13. Mirmira RG, Sims EK, Syed F, Evans-Molina C. Biomarkers of $\beta$-Cell Stress and Death in Type 1 Diabetes. Curr Diab Rep. 2016 Oct;16(10):95.

14. Sims EK, Chaudhry Z, Watkins R, Syed F, Blum J, Ouyang F, et al. Elevations in the Fasting Serum Proinsulin-to-C-Peptide Ratio Precede the Onset of Type 1 Diabetes. Diabetes Care. 2016 Sep;39(9):1519-26.

15. Anderson MS, Bluestone JA. THE NOD MOUSE: A Model of Immune Dysregulation. Annual Review of Immunology. 2005;23(1):447-85.

16. Kodama K, Butte AJ, Creusot RJ, Su L, Sheng D, Hartnett M, et al. TISSUE- AND AGESPECIFIC CHANGES IN GENE EXPRESSION DURING DISEASE INDUCTION AND PROGRESSION IN NOD MICE. Clin Immunol. 2008 Nov;129(2):195-201.

17. Wu J, Kakoola DN, Lenchik NI, Desiderio DM, Marshall DR, Gerling IC. Molecular Phenotyping of Immune Cells from Young NOD Mice Reveals Abnormal Metabolic Pathways in the Early Induction Phase of Autoimmune Diabetes. PLoS One. 2012 Oct 11;7(10):e46941.

18. Ize-Ludlow D, Lightfoot YL, Parker M, Xue S, Wasserfall C, Haller MJ, et al. Progressive Erosion of $\beta$-Cell Function Precedes the Onset of Hyperglycemia in the NOD Mouse Model of Type 1 Diabetes. Diabetes. 2011 Aug;60(8):2086-91.

19. Lennon GP, Bettini M, Burton AR, Vincent E, Arnold PY, Santamaria P, et al. T Cell Islet Accumulation in Type 1 Diabetes Is a Tightly Regulated, Cell-Autonomous Event. Immunity. 2009 Oct;31(4):643-53.

20. Tisch R, Yang X-D, Singer SM, Liblau RS, Fugger L, McDevitt HO. Immune response to glutamic acid decarboxylase correlates with insulitis in non-obese diabetic mice. Nature. 1993 Nov;366(6450):72-5.

21. Carrero JA, Calderon B, Towfic F, Artyomov MN, Unanue ER. Defining the Transcriptional and Cellular Landscape of Type 1 Diabetes in the NOD Mouse. PLoS One. 2013 Mar 26;8(3):e59701.

22. Campellone KG, Webb NJ, Znameroski EA, Welch MD. WHAMM Is an Arp2/3 Complex Activator That Binds Microtubules and Functions in ER to Golgi Transport. Cell. $2008 \mathrm{Jul}$ 11;134(1):148-61.

23. Piotrowski JT, Gomez TS, Schoon RA, Mangalam AK, Billadeau DD. WASH knockout T cells demonstrate defective receptor trafficking, proliferation, and effector function. Mol Cell Biol. 2013 Mar;33(5):958-73.

24. Zhang $Y$, Shen $H$, Liu $H$, Feng $H$, Liu $Y$, Zhu $X$, et al. Arp $2 / 3$ complex controls T cell homeostasis by maintaining surface TCR levels via regulating TCR+ endosome trafficking. Sci Rep. 2017 Aug 21;7(1):8952. 
25. Segerstolpe Å, Palasantza A, Eliasson P, Andersson E-M, Andréasson A-C, Sun X, et al. Single-Cell Transcriptome Profiling of Human Pancreatic Islets in Health and Type 2 Diabetes. Cell Metabolism. 2016 Oct;24(4):593-607.

26. Tarry-Adkins JL, Chen J, Jones RH, Smith NH, Ozanne SE. Poor maternal nutrition leads to alterations in oxidative stress, antioxidant defense capacity, and markers of fibrosis in rat islets: potential underlying mechanisms for development of the diabetic phenotype in later life. FASEB j. 2010 Aug;24(8):2762-71.

27. Subramanian Vignesh K, Deepe GS. Metallothioneins: Emerging Modulators in Immunity and Infection. Int J Mol Sci. 2017 Oct 23;18(10):2197.

28. Wu C, Pot C, Apetoh L, Thalhamer T, Zhu B, Murugaiyan G, et al. Metallothioneins negatively regulate IL-27-induced type 1 regulatory T-cell differentiation. PNAS. 2013 May 7;110(19):7802-7.

29. Kleppe R, Martinez A, Døskeland SO, Haavik J. The 14-3-3 proteins in regulation of cellular metabolism. Seminars in Cell \& Developmental Biology. 2011 Sep 1;22(7):713-9.

30. Lim GE, Piske M, Johnson JD. 14-3-3 proteins are essential signalling hubs for beta cell survival. Diabetologia. 2013 Apr 1;56(4):825-37.

31. Jang I, Pottekat A, Poothong J, Yong J, Lagunas-Acosta J, Charbono A, et al. PDIA1/P4HB is required for efficient proinsulin maturation and $B$ cell health in response to diet induced obesity. Malhotra V, Gilmore R, Mirmira R, editors. eLife. 2019 Jun 11;8:e44528.

32. Papa FR. Endoplasmic Reticulum Stress, Pancreatic $\beta$-Cell Degeneration, and Diabetes. Cold Spring Harb Perspect Med. 2012 Sep 1;2(9):a007666.

33. Yusta B, Baggio LL, Estall JL, Koehler JA, Holland DP, Li H, et al. GLP-1 receptor activation improves $\beta$ cell function and survival following induction of endoplasmic reticulum stress. Cell Metabolism. 2006 Nov 1;4(5):391-406.

34. Ahn EH, Kim DW, Shin MJ, Ryu EJ, Yong JI, Chung SY, et al. Tat-ATOX1 inhibits streptozotocin-induced cell death in pancreatic RINm5F cells and attenuates diabetes in a mouse model. Int J Mol Med. 2016 Jul;38(1):217-24.

35. Zhao C, Wang M, Huang J, Jia Z, Zhao X, Li E, et al. Integrative analysis of proteomic and metabonomics data for identification of pathways related to Rhizoma Paridis-induced hepatotoxicity. Sci Rep. 2020 Apr 16;10(1):6540.

36. Hou X, Nozumi M, Nakamura H, Igarashi M, Sugiyama S. Coactosin Promotes F-Actin Protrusion in Growth Cones Under Cofilin-Related Signaling Pathway. Frontiers in Cell and Developmental Biology. 2021;9:1633. 
37. Bresnick AR, Weber DJ, Zimmer DB. S100 proteins in cancer. Nat Rev Cancer. 2015 Feb;15(2):96-109.

38. Sedaghat F, Notopoulos A. S100 protein family and its application in clinical practice. Hippokratia. 2008;12(4):198-204.

39. Ehrlich AK, Pennington JM, Wang X, Rohlman D, Punj S, Löhr CV, et al. Activation of the Aryl Hydrocarbon Receptor by 10-Cl-BBQ Prevents Insulitis and Effector T Cell Development Independently of Foxp3+ Regulatory T Cells in Nonobese Diabetic Mice. The Journal of Immunology. 2016 Jan 1;196(1):264-73.

40. Wolf G, Aumann N, Michalska M, Bast A, Sonnemann J, Beck JF, et al. Peroxiredoxin III protects pancreatic $\beta$ cells from apoptosis. Journal of Endocrinology. 2010 Nov 1;207(2):163-75.

41. Elumalai S, Karunakaran U, Moon JS, Won KC. High glucose-induced PRDX3 acetylation contributes to glucotoxicity in pancreatic $\beta$-cells: Prevention by Teneligliptin. Free Radic Biol Med. 2020 Nov 20;160:618-29.

42. Cole KS, Grandjean JMD, Chen K, Witt CH, O'Day J, Shoulders MD, et al. Characterization of an A-Site Selective Protein Disulfide Isomerase A1 Inhibitor. Biochemistry. $2018 \mathrm{Apr}$ 3;57(13):2035-43.

43. Campos JLO, Doratioto TR, Videira NB, Ribeiro Filho HV, Batista FAH, Fattori J, et al. Protein Disulfide Isomerase Modulates the Activation of Thyroid Hormone Receptors. Frontiers in Endocrinology. 2019;9:784.

44. Mathews CE, Xue S, Posgai A, Lightfoot YL, Li X, Lin A, et al. Acute Versus Progressive Onset of Diabetes in NOD Mice: Potential Implications for Therapeutic Interventions in Type 1 Diabetes. Diabetes. 2015 Nov;64(11):3885-90.

45. Armstrong JS, Steinauer KK, Hornung B, Irish JM, Lecane P, Birrell GW, et al. Role of glutathione depletion and reactive oxygen species generation in apoptotic signaling in a human B lymphoma cell line. Cell Death Differ. 2002 Mar;9(3):252-63.

46. Chetboun M, Abitbol G, Rozenberg K, Rozenfeld H, Deutsch A, Sampson SR, et al. Maintenance of redox state and pancreatic beta-cell function: role of leptin and adiponectin. J Cell Biochem. 2012 Jun;113(6):1966-76.

47. Kinchen JM, Ravichandran KS. Phagosome maturation: going through the acid test. Nat Rev Mol Cell Biol. 2008 Oct;9(10):781-95.

48. Chauss D, Brennan LA, Bakina O, Kantorow M. Integrin $\alpha$ V $\beta 5$-mediated Removal of Apoptotic Cell Debris by the Eye Lens and Its Inhibition by UV Light Exposure *. Journal of Biological Chemistry. 2015 Dec 18;290(51):30253-66. 
49. Eizirik DL, Sammeth M, Bouckenooghe T, Bottu G, Sisino G, Igoillo-Esteve M, et al. The human pancreatic islet transcriptome: expression of candidate genes for type 1 diabetes and the impact of pro-inflammatory cytokines. PLoS Genet. 2012;8(3):e1002552.

50. Russell MA, Redick SD, Blodgett DM, Richardson SJ, Leete P, Krogvold L, et al. HLA Class II Antigen Processing and Presentation Pathway Components Demonstrated by Transcriptome and Protein Analyses of Islet $\beta$-Cells From Donors With Type 1 Diabetes. Diabetes. 2019 May;68(5):988-1001.

51. Shrestha S, Saunders DC, Walker JT, Camunas-Soler J, Dai X-Q, Haliyur R, et al. Combinatorial transcription factor profiles predict mature and functional human islet $\alpha$ and $\beta$ cells. JCI Insight. 2021 Sep 22;6(18):e151621.

52. Yip L, Fuhlbrigge R, Alkhataybeh R, Fathman CG. Gene Expression Analysis of the PreDiabetic Pancreas to Identify Pathogenic Mechanisms and Biomarkers of Type 1 Diabetes. Front Endocrinol (Lausanne). 2020 Dec 23;11:609271.

53. Crèvecoeur I, Gudmundsdottir V, Vig S, Sodré FMC, D'Hertog W, Fierro AC, et al. Early differences in islets from prediabetic NOD mice: combined microarray and proteomic analysis. Diabetologia. 2017 Jan 12;1-15.

54. Malaguti C, La Guardia PG, Leite ACR, Oliveira DN, de Lima Zollner RL, Catharino RR, et al. Oxidative stress and susceptibility to mitochondrial permeability transition precedes the onset of diabetes in autoimmune non-obese diabetic mice. Free Radic Res. 2014 Dec;48(12):1494-504.

55. Chen L, Na R, Gu M, Salmon AB, Liu Y, Liang H, et al. Reduction of mitochondrial H2O2 by overexpressing peroxiredoxin 3 improves glucose tolerance in mice. Aging Cell. 2008;7(6):866-78.

56. Araujo TLS, Fernandes CG, Laurindo FRM. Golgi-independent routes support protein disulfide isomerase externalization in vascular smooth muscle cells. Redox Biology. 2017 Aug 1;12:1004-10.

57. Araujo TLS, Zeidler JD, Oliveira PVS, Dias MH, Armelin HA, Laurindo FRM. Protein disulfide isomerase externalization in endothelial cells follows classical and unconventional routes. Free Radical Biology and Medicine. 2017 Feb 1;103:199-208.

58. Zhou J, Wu Y, Wang L, Rauova L, Hayes VM, Poncz M, et al. The C-terminal CGHC motif of protein disulfide isomerase supports thrombosis. J Clin Invest. 2015 Nov 3;125(12):4391406.

59. Hahm E, Li J, Kim K, Huh S, Rogelj S, Cho J. Extracellular protein disulfide isomerase regulates ligand-binding activity of $\alpha \mathrm{M} \beta 2$ integrin and neutrophil recruitment during vascular inflammation. Blood. 2013 May 9;121(19):3789-800, S1-15. 
60. Yang M-L, Connolly SE, Gee R, Lam T, Kanyo J, Clarke SG, et al. Carbonyl Post-Translational Modification Associated with Early Onset Type 1 Diabetes Autoimmunity. bioRxiv. 2021 Jun $15 ; 2021.06 .15 .448522$.

61. Coppieters KT, Dotta F, Amirian N, Campbell PD, Kay TWH, Atkinson MA, et al. Demonstration of islet-autoreactive CD8 T cells in insulitic lesions from recent onset and long-term type 1 diabetes patients. J Exp Med. 2012 Jan 16;209(1):51-60.

62. Roep BO, Atkinson M, von Herrath M. Satisfaction (not) guaranteed: re-evaluating the use of animal models of type 1 diabetes. Nat Rev Immunol. 2004 Dec;4(12):989-97.

63. Leiter EH, von Herrath M. Animal models have little to teach us about type 1 diabetes: 2 . In opposition to this proposal. Diabetologia. 2004 Oct;47(10):1657-60.

64. Campbell-Thompson M, Fu A, Kaddis JS, Wasserfall C, Schatz DA, Pugliese A, et al. Insulitis and $\beta$-Cell Mass in the Natural History of Type 1 Diabetes. Diabetes. 2016 Mar;65(3):71931.

65. Lam CJ, Jacobson DR, Rankin MM, Cox AR, Kushner JA. $\beta$ Cells Persist in T1D Pancreata Without Evidence of Ongoing $\beta$-Cell Turnover or Neogenesis. J Clin Endocrinol Metab. 2017 Feb 27;102(8):2647-59.

66. Chen Y-G, Mathews CE, Driver JP. The Role of NOD Mice in Type 1 Diabetes Research: Lessons from the Past and Recommendations for the Future. Frontiers in Endocrinology. 2018;9:51.

67. Rui J, Deng S, Arazi A, Perdigoto AL, Liu Z, Herold KC. $\beta$ Cells that Resist Immunological Attack Develop during Progression of Autoimmune Diabetes in NOD Mice. Cell Metab. 2017 Mar 7;25(3):727-38.

68. Stull ND, Breite A, McCarthy R, Tersey SA, Mirmira RG. Mouse islet of Langerhans isolation using a combination of purified collagenase and neutral protease. J Vis Exp. 2012 Sep $7 ;(67): 4137$.

69. Nakayasu ES, Syed F, Tersey SA, Gritsenko MA, Mitchell HD, Chan CY, et al. Comprehensive Proteomics Analysis of Stressed Human Islets Identifies GDF15 as a Target for Type 1 Diabetes Intervention. Cell Metab. 2020 Feb 4;31(2):363-374.e6.

70. Haskins K, Portas M, Bergman B, Lafferty K, Bradley B. Pancreatic islet-specific T-cell clones from nonobese diabetic mice. Proc Natl Acad Sci U S A. 1989 Oct;86(20):8000-4.

71. Bone RN, Gai Y, Magrioti V, Kokotou MG, Ali T, Lei X, et al. Inhibition of Ca2+-independent phospholipase $A 2 \beta$ (iPLA2 $\beta$ ) ameliorates islet infiltration and incidence of diabetes in NOD mice. Diabetes. 2015 Feb;64(2):541-54. 
72. Ocaña GJ, Pérez L, Guindon L, Deffit SN, Evans-Molina C, Thurmond DC, et al. Inflammatory stress of pancreatic beta cells drives release of extracellular heat-shock protein $90 \alpha$. Immunology. 2017 Jun 1;151(2):198-210.

73. Kuster DWD, Barefield D, Govindan S, Sadayappan S. A Sensitive and Specific Quantitation Method for Determination of Serum Cardiac Myosin Binding Protein-C by Electrochemiluminescence Immunoassay. J Vis Exp. 2013 Aug 8;(78):50786.

74. Panicker G, Rajbhandari I, Gurbaxani BM, Querec TD, Unger ER. Development and evaluation of multiplexed immunoassay for detection of antibodies to HPV vaccine types. J Immunol Methods. 2015 Feb;417:107-14. 


\section{Figure 1}

\section{Schematic workflow}

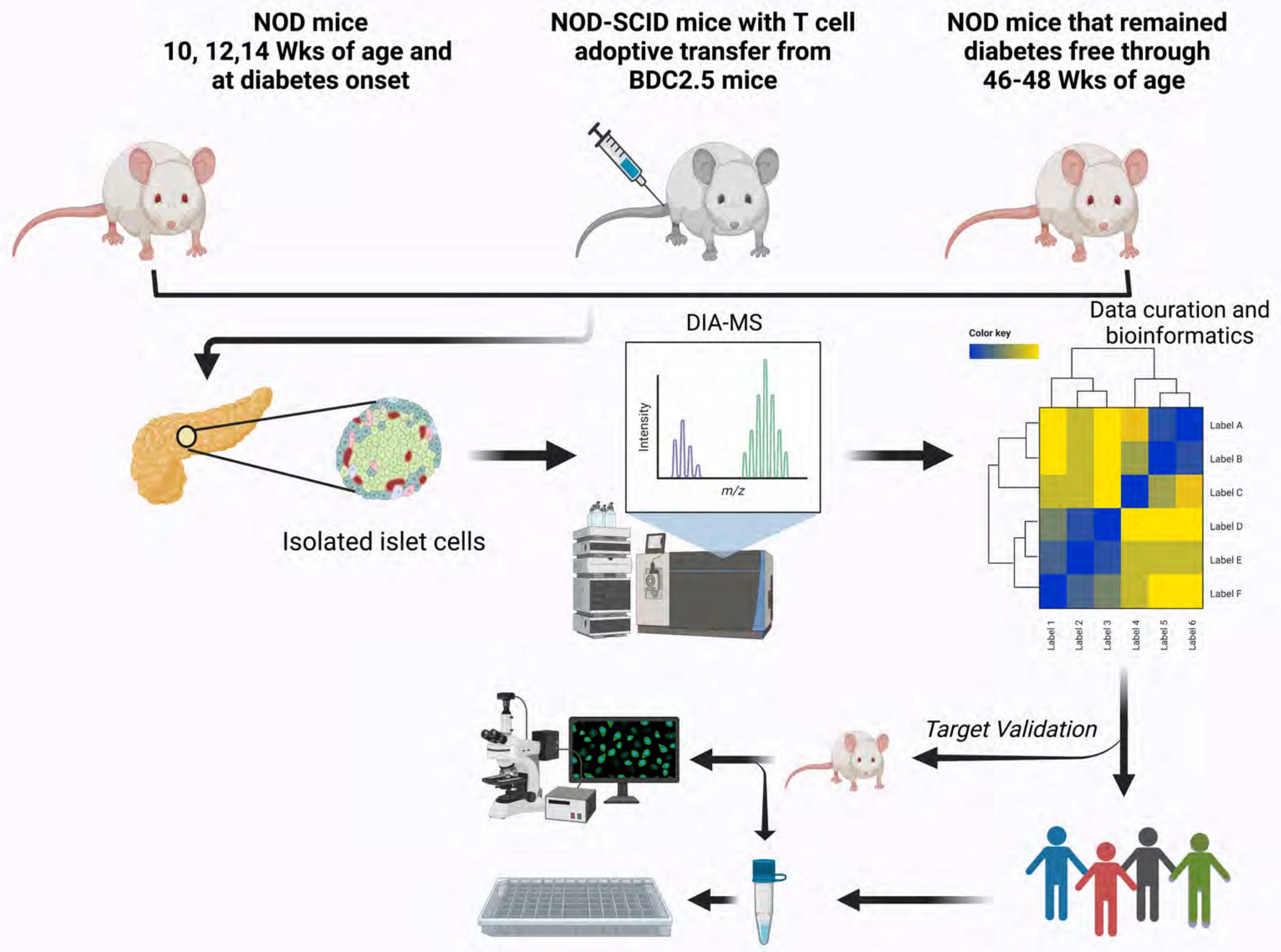


Figure 2

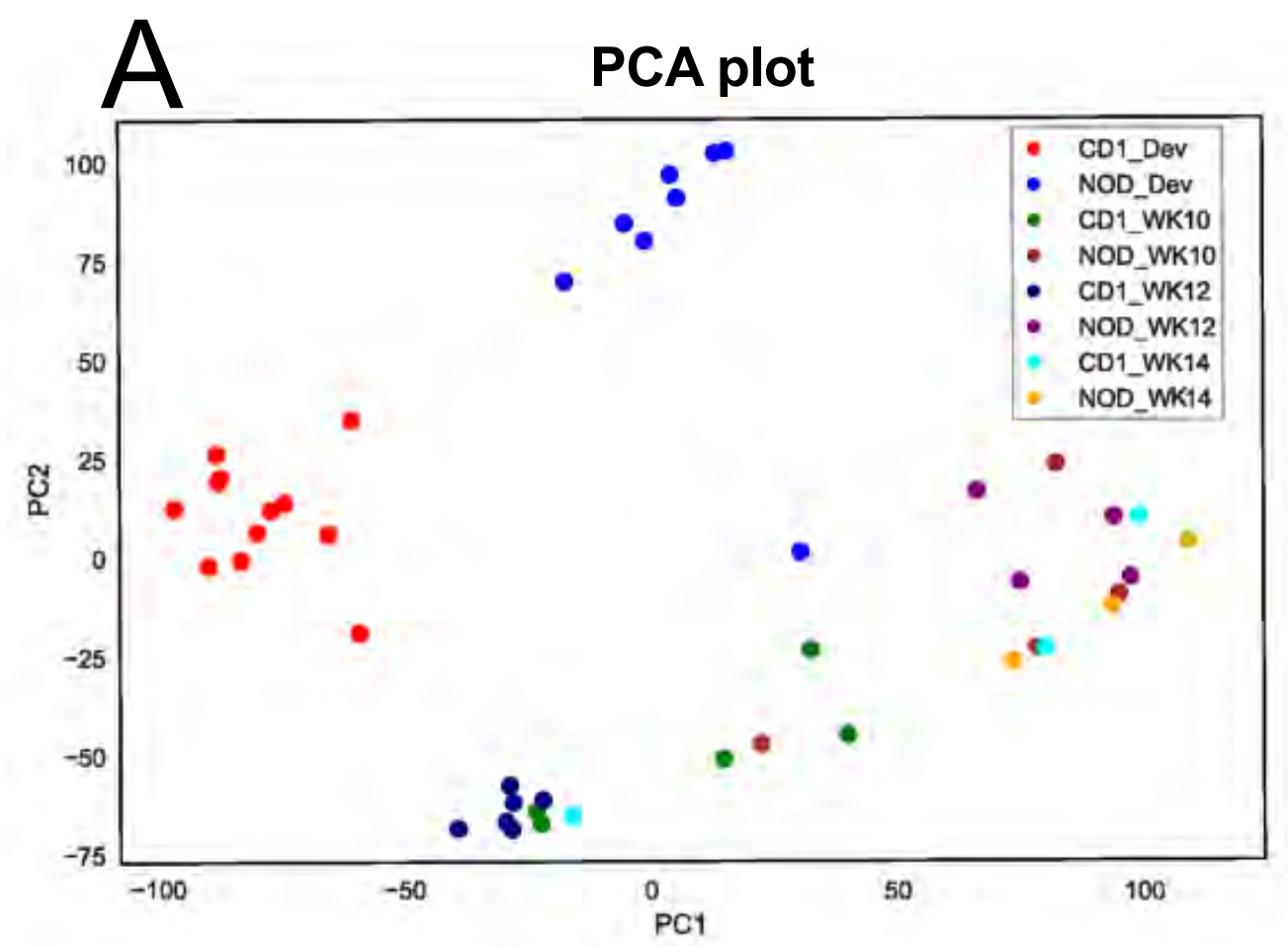

B

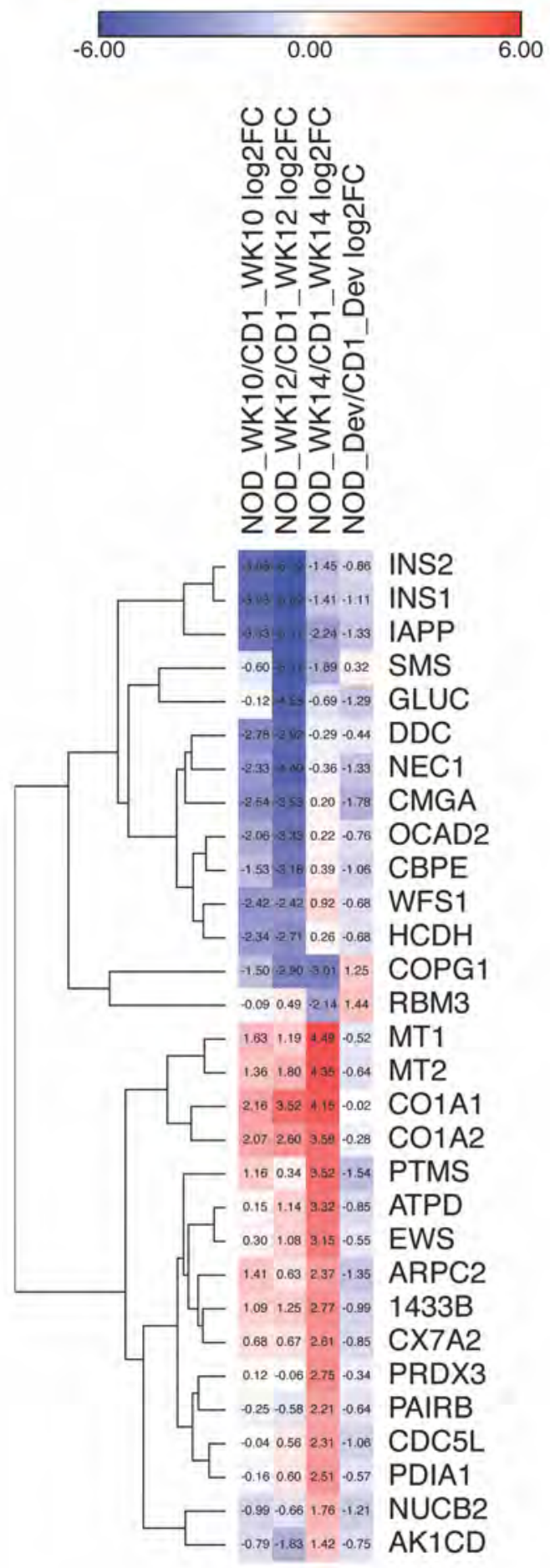




\section{Up-Regulated Pathways}

A

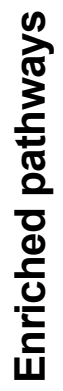

B

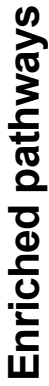

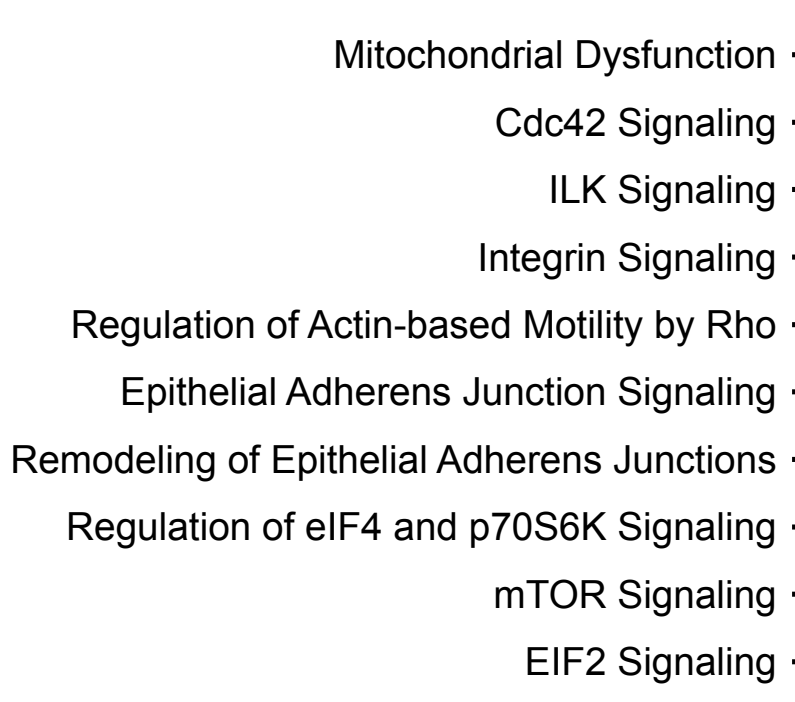

0

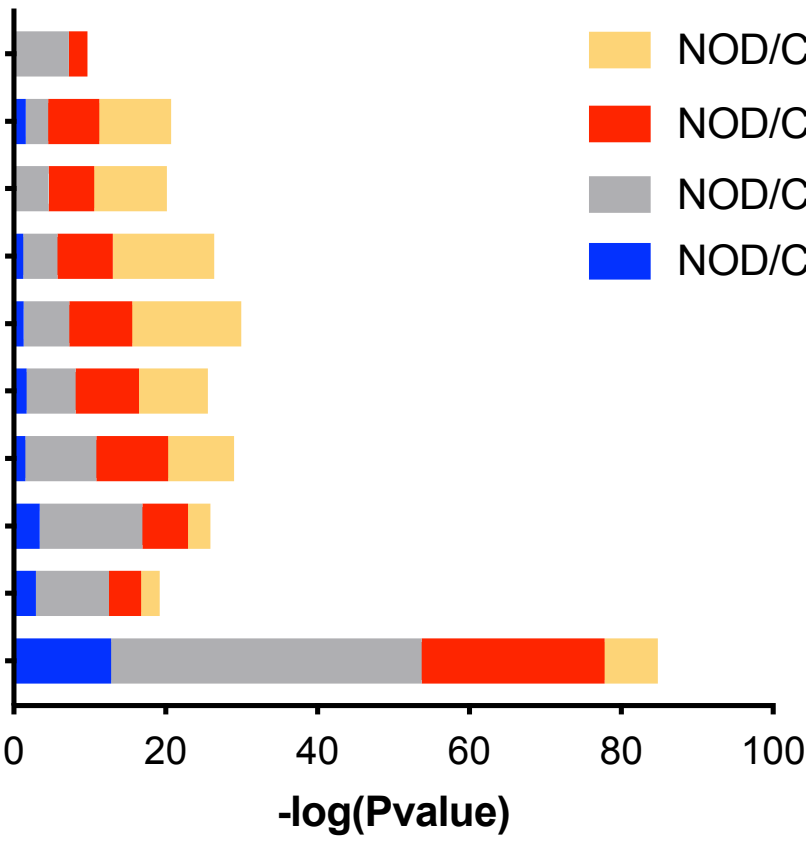

Down-Regulated Pathways

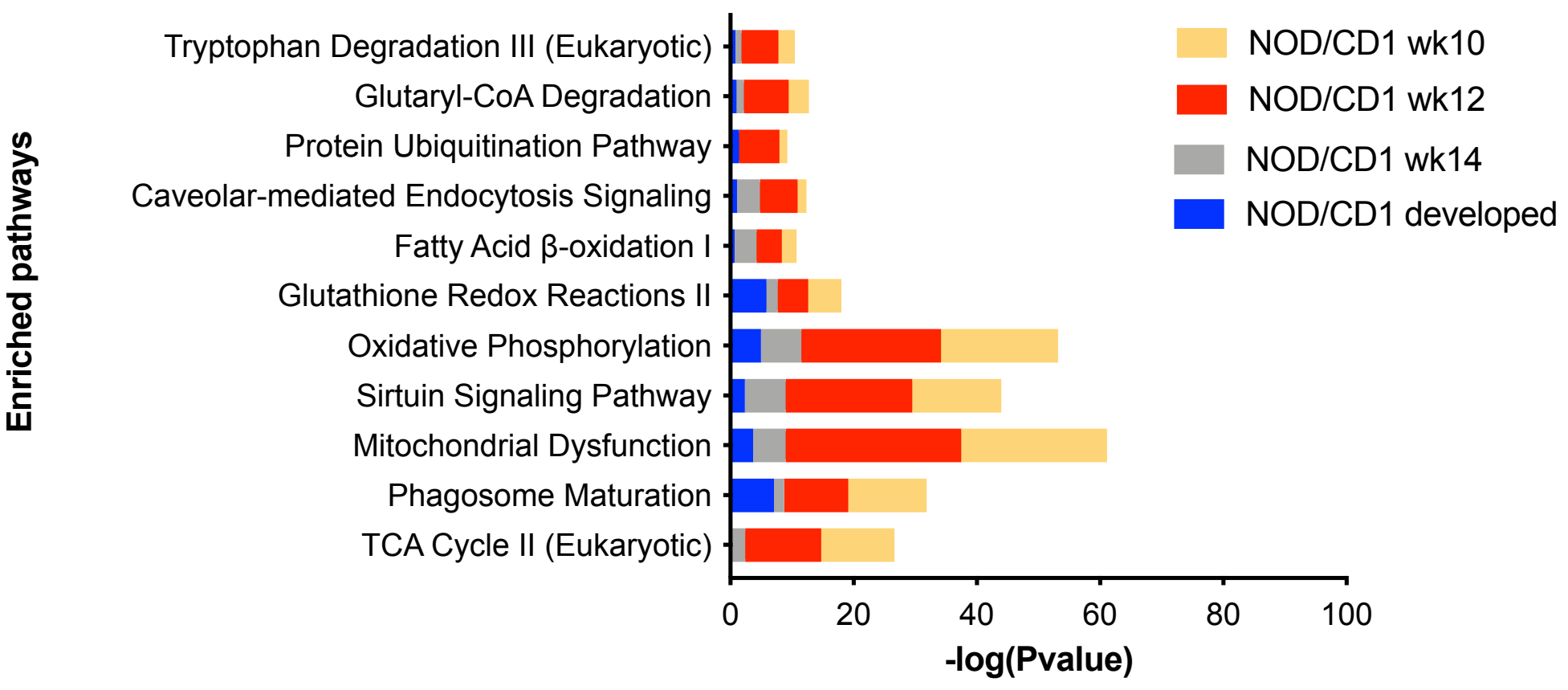


Figure 4

A NOD-Diabetes

(559)

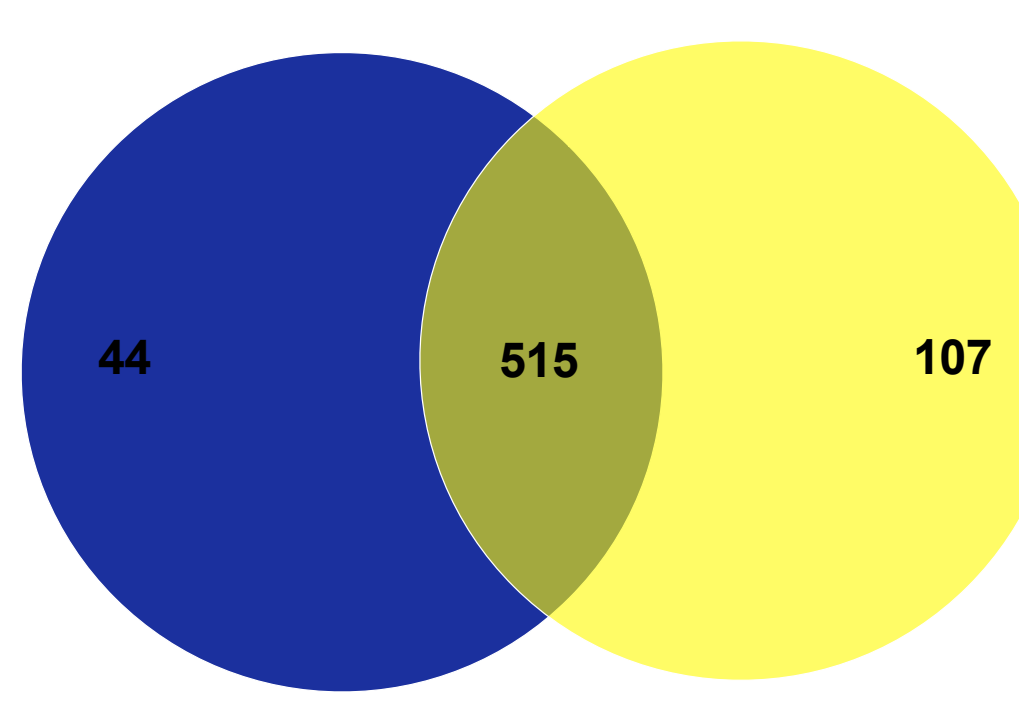

NOD-BDC2.5 Induced

(622)

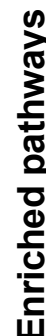

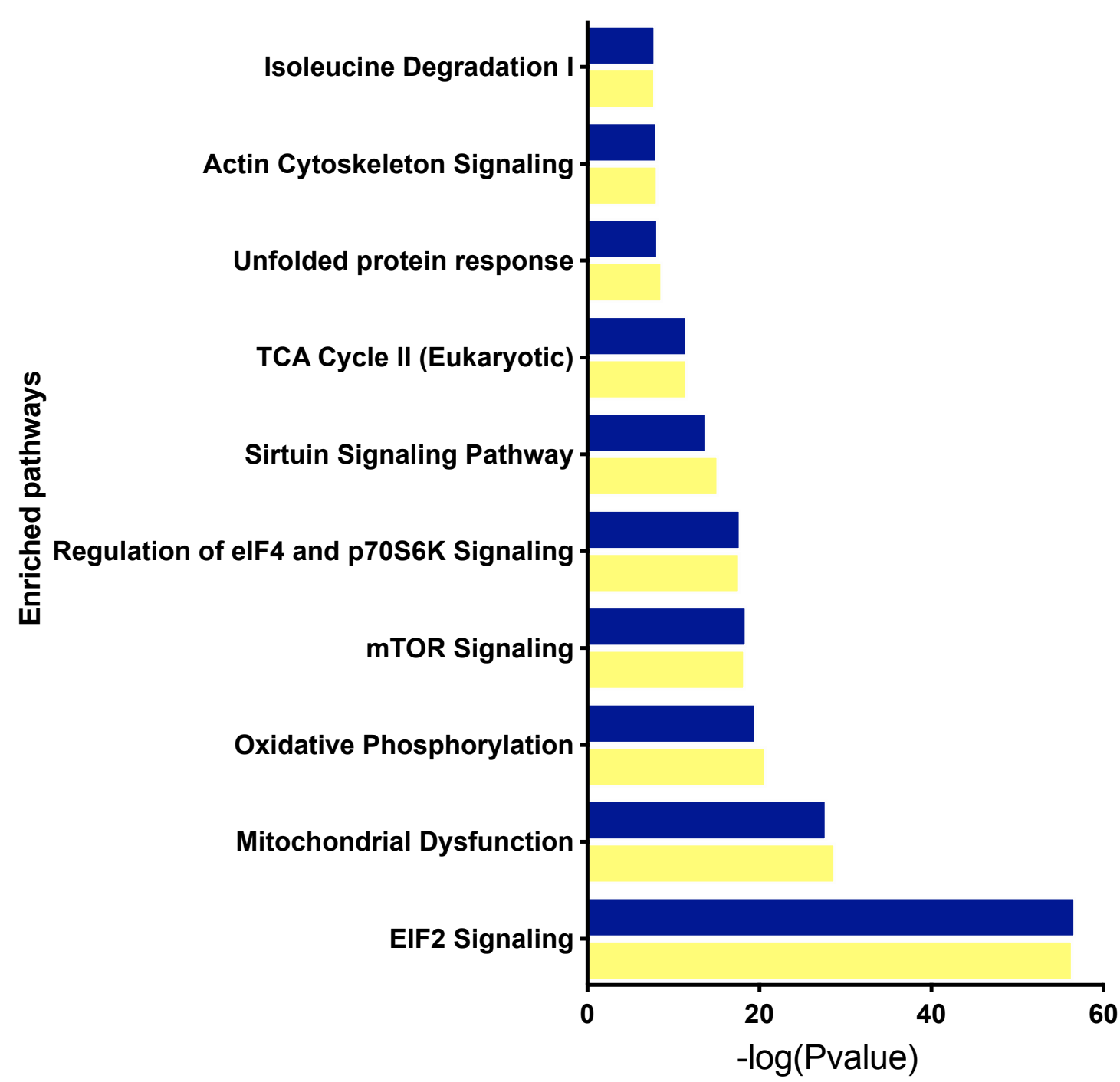

NOD-Diabetes 
Figure 5 A
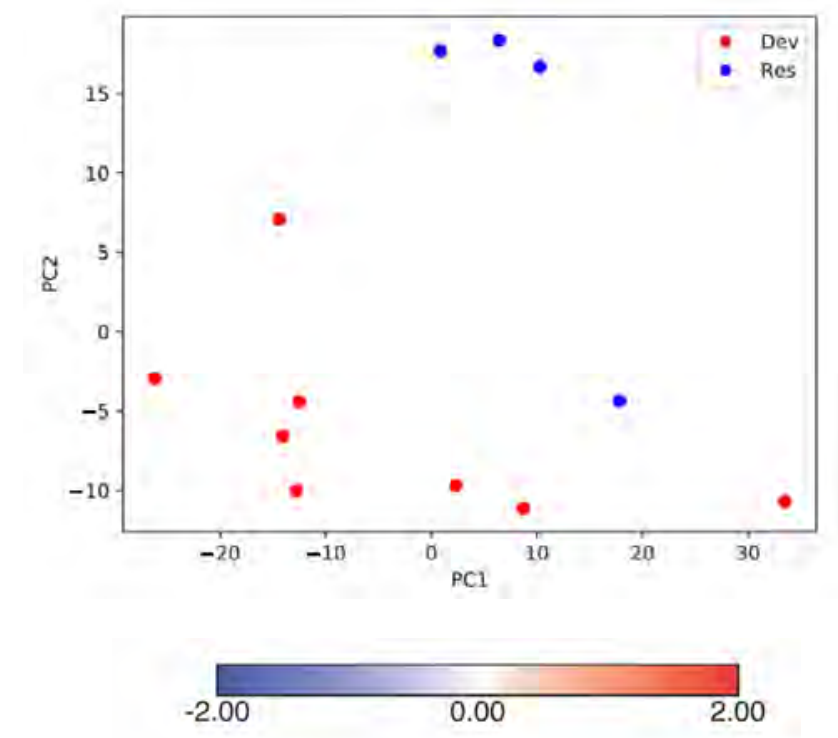

B

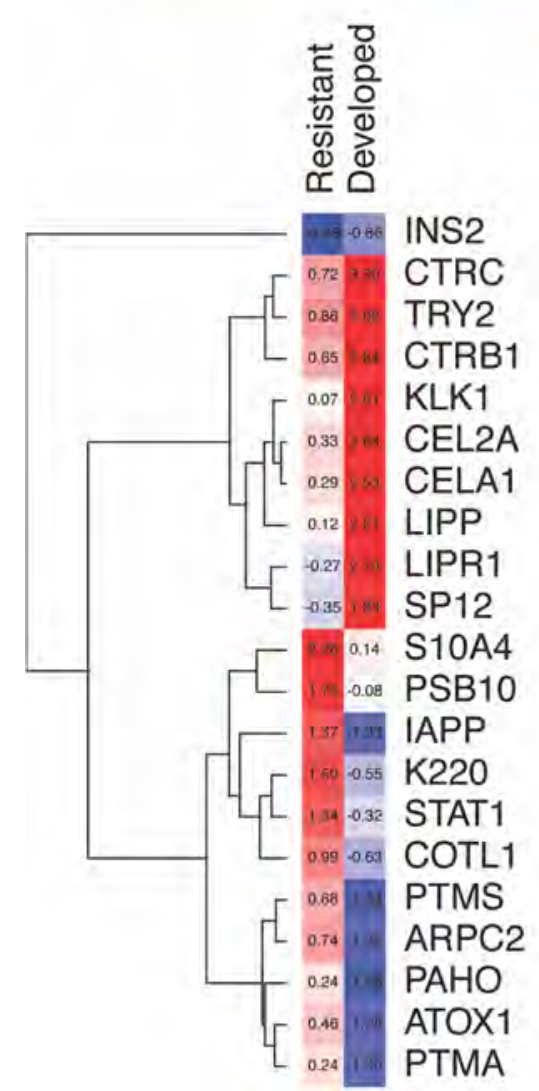

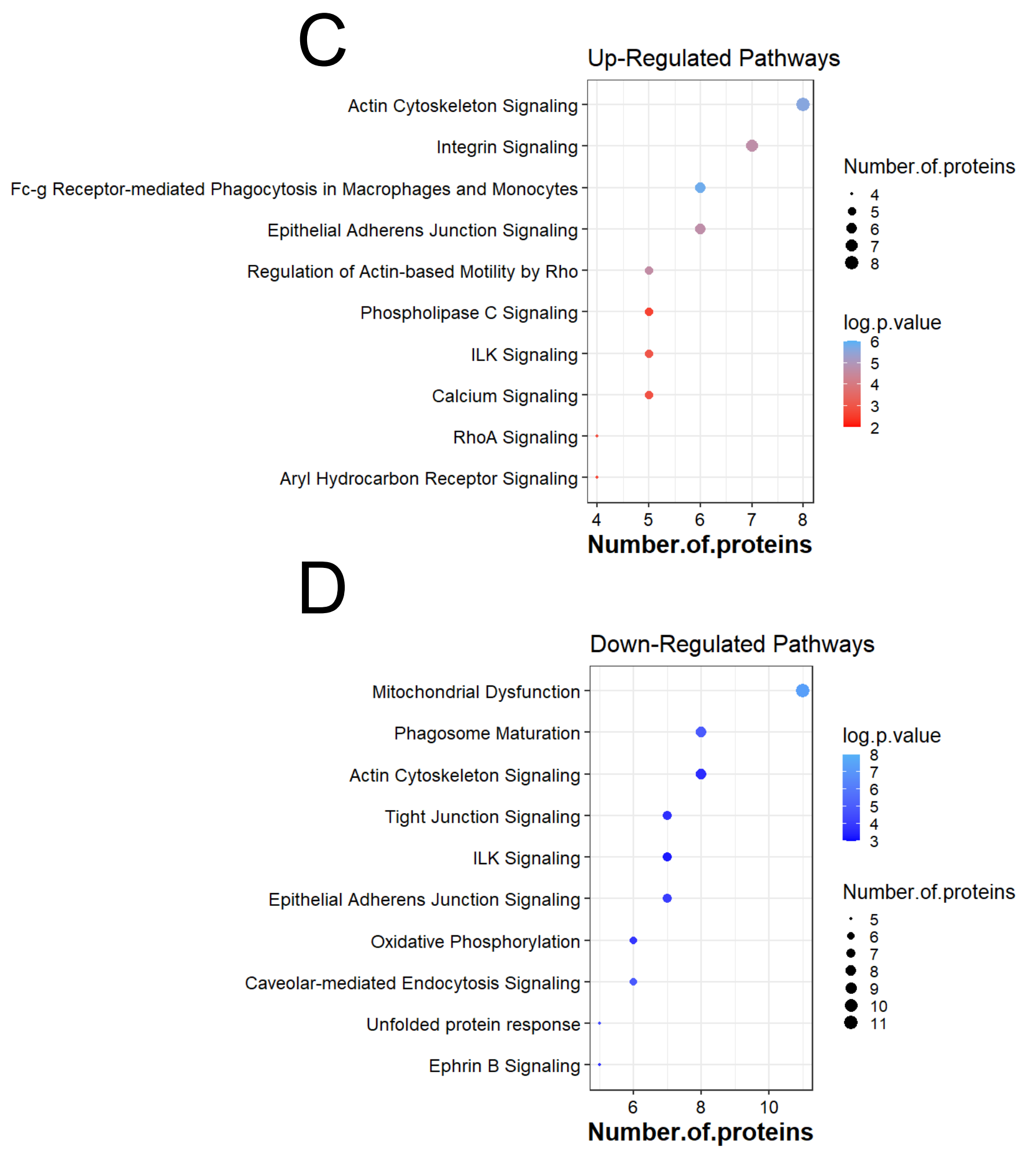




\section{Figure 6}
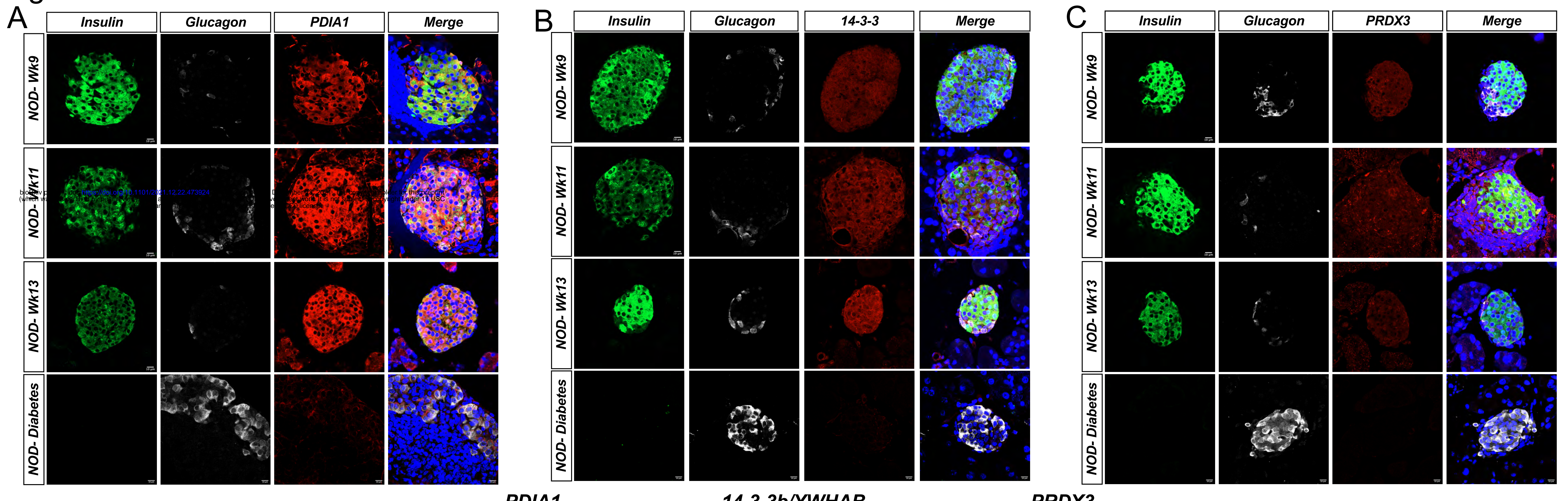

PDIA1

14-3-3b/YWHAB

PRDX3

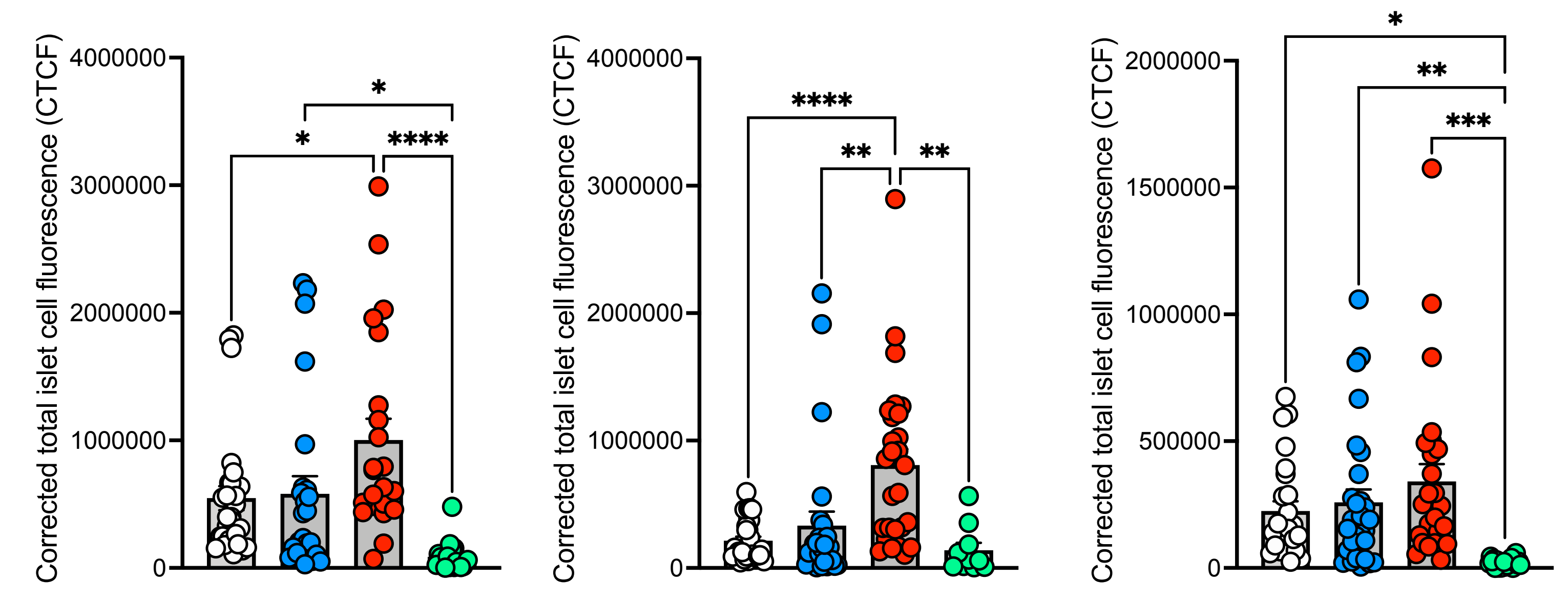



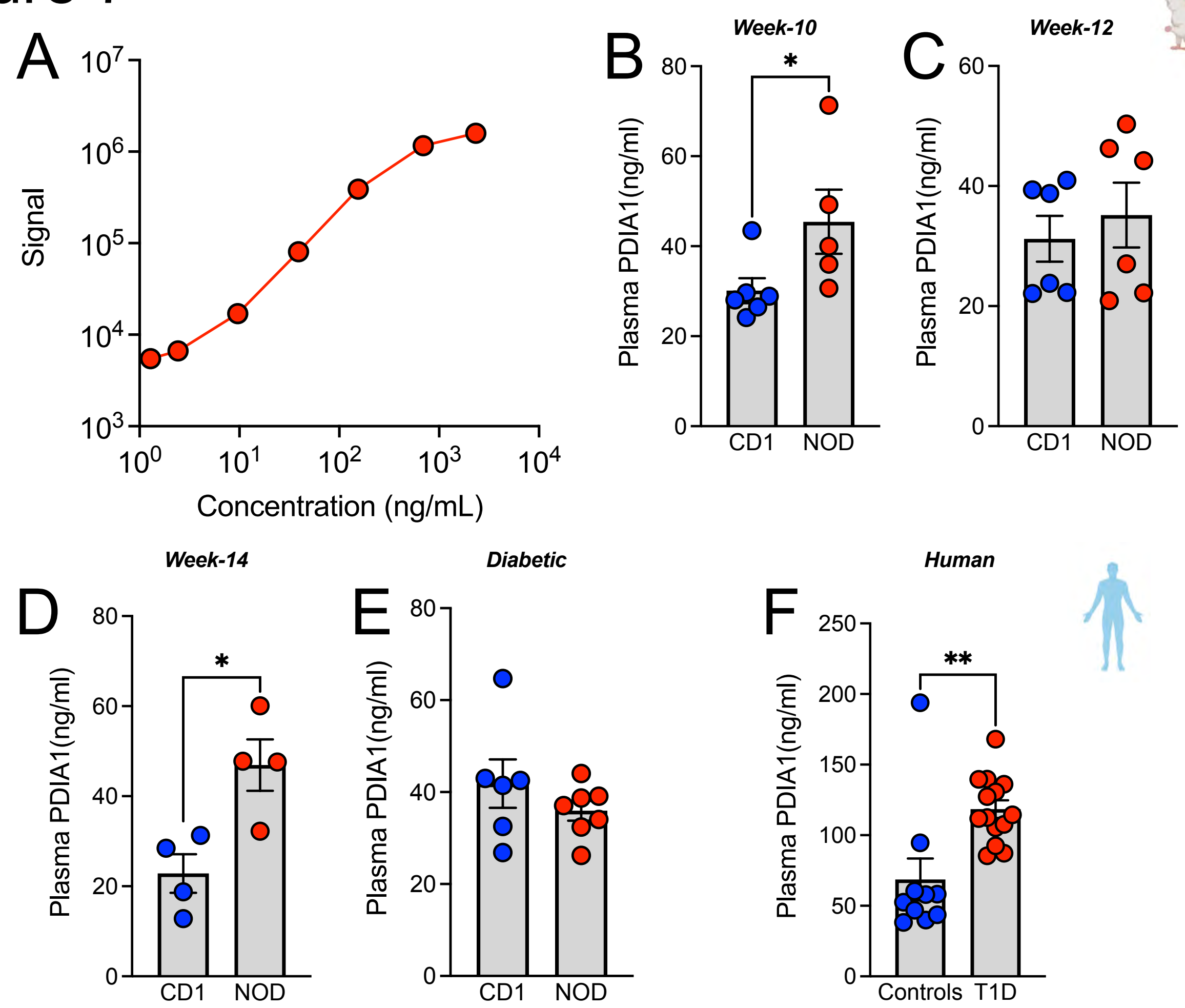
bioRxiv preprint doi: https://doi.org/10.1101/2021.12.22.473924; this version posted December 23, 2021. The copyright holder for this preprint (which was not certified by peer review) is the author/funder. This article is a US Government work. It is not subject to copyright under 17 USC 105 and is also made available for use under a CCO license.

Table 1

\begin{tabular}{|l|l|l|l|l|}
\hline & Age (years) & $\begin{array}{l}\text { Gender } \\
(\mathrm{M} / \mathrm{F})\end{array}$ & BMI\% & $\begin{array}{l}\text { Diabetes } \\
\text { (Yes/No) }\end{array}$ \\
\hline Healthy Controls & $12.1 \pm 4.20 \mathrm{yrs}$ & $7 \mathrm{M} / 6 \mathrm{~F}$ & $66.3 \pm 24.33$ & No \\
\hline New Onset T1D & $11.57 \pm 4.05 \mathrm{yrs}$ & $6 \mathrm{M} / 4 \mathrm{~F}$ & $55.42 \pm 28.37$ & Yes \\
\hline
\end{tabular}

Table 2

\begin{tabular}{|l|l|l|}
\hline Company & Catalogue Number & Antibody/recombinant protein \\
\hline Sigma-Aldrich & HPA018884-100UL & Antibody \\
\hline Thermo Scientific & Catalog \# MA3-019 & Antibody \\
\hline LSBio & LS-F72880-500 & P4HB ELISA Development Kit \\
\hline Cell Signaling & Cat \# 350 & Antibody \\
\hline ProsPec & Cat\#ENZ-252 & Recombinant protein \\
\hline LSBio & Cat\#LS-G22049 & Recombinant protein \\
\hline
\end{tabular}

